\title{
Reflexive Engine to Lock the System for Driving While Intoxicated - Simulation by Using LabVIEW
}

$\underline{\text { https://doi.org/10.3991/ijoe.v16i13.18567 }}$

\author{
K. Bharath Kumar $\left.{ }^{(}\right)$, Ch. Sudha Mani, Mohd. Abdul Naqi, \\ S. Mallesh Narayana \\ CMR Technical Campus, Hyderabad, India \\ kammarabharathkumaregmail.com
}

\begin{abstract}
Drunken driving is a major issue due to which many road accidents are occurring. To overcome these many kinds of research are going on and we also tried to develop a reflexive engine locking system in this paper we have developed a system through which when a person tries to drive by consuming alcohol will experience an automatic engine lock. By implementing this we can save the lives of passengers as well as pedestrians and other people too. Today's situation is worsening like for every thirty minutes accidents are happening and taking the lives of many innocent people. To avoid this, we are trying to implement a prototype for alcohol detection for drunk and drive. Based on the threshold set, an alcohol breath analyzer sense level of alcohol consumed by the driver and if it crosses the limit set it will automatically lock the engine. Due to the drowsiness of driver and consumption of alcohol more accidents are happening. Because of this more lives are at risk. This design implements a model that saves the lives of people inside and outside the vehicle.
\end{abstract}

Keywords-MQ-3 Alcohol sensor, Arduino Uno ATmega328, LCD, MyRIO, and LabVIEW

\section{Introduction}

In today's life accidents are mostly happening due to alcohol consumption. Most of the road accidents now a day are due to the influence of alcohol and this may lead to serious injuries and even deaths [1]. In Europe, due to drunk and drive thousands of accident deaths cases coming every year. Due to alcohol consumed $31.1 \%$ of driving accidents death is happening in the USA. In China, as per Li et al. these death cases are approximately $34.12 \%$ of road accidents are related to alcohol consumption [4]. Drunk driving may lead to serious accidents and causes injuries and deaths. Because of little consumption of alcohol consumption is leading to serious road accidents when compared to non-alcoholic motorist [5]. So, many countries working to find the solution for the drunk and driving problem for many years, making tough laws and educating them on this concern. These laws have been introduced not to drive after drinking and have imposed severe penalties on violators. As per the legal limits for BAC are between $0.01 \%$ to $0.08 \%$. And these limits are given in some countries like for example, Sweden 
is $0.021 \%$; Israel is $0.049 \%$, Korea is $0.03 \%$, Australia is $0.03 \%$; Canada is $0.079 \%$, England, Mexico, and the United States is $0.04 \%$. In China, the limit for driving with a BAC higher than $0.022 \%$ is defined as drink driving and the driver will be considered as a violator. And if driving with a BAC higher than $0.08 \%$ is to be treated as drunken driving and it belongs to an unlawful act. It is very difficult to avoid drunk and drive death cases. Consumption of heavy alcohol will affect the driver's awareness, concentration, legal opinion, reaction, and cognition. These are related to driving capabilities. From this, it can be completely concluded that even less alcohol consumption significantly affects driving skills such as awareness, driving behavior, and vision [2]. At this time, the information process and attention of drivers were heavily affected by the consumption of alcohol. As per the demonstration of Nash, drivers would be distracted by alcohol when they were asked to complete simple tasks [3]. Due to the consumption of alcohol, it can be indicated clearly that alcohol could negatively affect drivers' minds like calculation of distance and depth of perception [4-9]. Consumption of alcohol affects visual angles and most probably when it comes to the mind like moving objects and the process of different information at a time $[10,11]$. It is found that alcohol consumption will affect many Parameters like the mind will not be taken spontaneous decisions, no spot reaction times, awareness, visual angle searches, and no logical reasoning [12].

Consumption of Alcohol not only affects above mention parameters but also causes a decline in the performance of the driver. Linotile et al [13] proposed a driver's ability will affect when the BAC level of $0.035 \%$. Due to the driver's handshaking and not in a standing manner at a BAC level of $0.06 \%$ [14], due to which accidents occur. Some of the research fellows are found that alcohol will affects behaviors like guidance and damper in the BAC level between $0.049 \%$ to $0.11 \%$ [15-17]. The impairment of guidance and damper control ability loss due to alcohol consumption. Fillmore et al [18] revealed that alcohol consumption will significantly affect the driving work, which includes deviation of the roadway, crossings of line, steering rotation, and uncontrol of the speed of limit. Chamberlain and Solomon [7] concluded that consumption of alcohol affects steering rotation control and damper behavior and it disturbs the vigilance of the driver. Based on the conclusions of these many researchers of the research fellows explained the consumption of alcohol in different BAC levels to avoid the accidences. But some of the researchers completely against these BAC levels. Because these levels are not considered for all the drunk and drive cases, some of the drivers have great mind control. So how these levels affect the driver mindset. These levels are purely related to mind control of drivers. In this research article, we mainly focused on the driving performance of the driver and straight roadway segment, these are the most common driving process accidence on road. To analyze the driving performance. Some of the researchers are conducted experiments. Based on this experiment researchers find and investigated driving status and vehicle traveling condition parameters and performance. Based on the investigation and results provided in the prototype of driving work and drunk, driving status provides a normal position. The main aim of these articles is followed: (1) to summarize the gestures mindset under consuming alcohol, (2) driving work is analyzed based on BAC levels, and (3) try to analyze and identified the driving 
status of the driver based on performance. The results are used as a reference for designing the alcohol detection devices and try to prevent damage that can be caused by drunk and drive.

\section{$2 \quad$ Project Analysis}

\section{$2.1 \quad$ Existing method}

In our proposed design system, three different technics are used to provide security for automobiles. Those three technics are electronics deflection, vehicle scanning system, and car buzzer. Due to including these techniques in the manufacturing in-vehicle system, total manufacture cost is increased. This cost is very high compared with the proposed prototype system. In the proposed method, easily deactivate the buzzer alarm in the vehicle security system. But in the developing countries home need vehicle market is high and normal people cannot access the high-cost security system. In today's automobile life industry safety is a major role. In the safety security system, which identifies the drowsiness of the driver. It is a big challenge for the design of the security system. This drowsiness is identified by image process technology. In this image processing eye movement and face detection by yawn all done using Open and Ego with Visual Studio 2013. Drunken driver state detection by using an alcohol sensor. In the driving time when drivers get drowsiness, an alarm is generated alarm, and surrounded co-passengers get vibrator alert. If these alerts get turned off 3 times continuously within a specified time interval then the vehicle engine is switched off automatically. In the previous system, in any vehicle detection of alcohol is not proposed. So, anyone consumes alcohol and do the driving. So only traffic police will do the test to identify these types of peoples.

\subsection{Proposed method}

In this proposed system mostly, we will use MQ- 3 Sensor and MYRIO by this two equipment we will design the code after installing LabVIEW. Then we have to design according to the required components which we require in LabVIEW tools. Mostly we can select the components from Boolean and control of MYRIO instruments. After selecting tools design according to block diagram, we have to mention one meter in that design make to use not gate to get true and false statement so that we can observe the output in the front panel and we get readings output practically.

- The Grove - Gas Sensor (MQ3) is a gas leakage detection (in the home and industry) module. This sensor is suitable for detecting hazardous gases like Alcohol, Benzene, CH4, Hexane, LPG, CO, etc.

- MQ3 Sensor is a high sensitivity that senses effectively and fast response time give results in no time using which gives the result as early as possible. By adjusting the potentiometer in the sensor, the sensitivity and response time of the sensor is changed. 
- The alarm is used for the buzzer, it starts to works and gives the indication when alcohol is identified.

- By using MYRIO and Alcohol detection sensor we can lock the engine.

- Using New Technology software, we may reduce our time.

The Designed system contains an MYRIO, this is acts as a processor to every component and used to design in block diagram window and after designing the code connected to the hardware requirement like LED, an alcohol sensor, a 5 volts DC power supply, and a LED. Whenever the processor system is switch ON, the GREEN LED displays i.e. system tells that "No Alcohol detected" and the vehicle engine we will starts. But whereas when the alcohol sensor detects any alcohol content, the green LED starts to blink and the RED LED will glow and the accelerator meter automatically sets to zero reading, making the vehicle engine OFF and the red LED glow and displays "Alcohol is Detected".

\section{Components Description}

\subsection{Alcohol sensor}

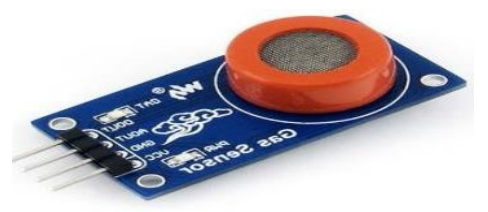

Fig. 1. MQ3 Sensor

In our breath any alcohol is present, this sensor will help to identify these contents. This sensor has a good and very quick response time. It has very good security inside of the sensor. Based on alcohol concentration this sensor gives a resistive analog signal as output.

\subsection{My RIO}

My Rio is a portable device that can be used by students and researchers. It can be easily used for the control and design of electromechanical devices like robots. This device is more suitable for many systems like quite a response and more efficient systems. Its resonance operates frequency $667 \mathrm{MHz}$ MY RIO consists of a dual-core processor with ARM Cortex. MY RIO consists of an A9 programmable processor with Xilinx's latest Field Programmable Gate Array (FPGA). 


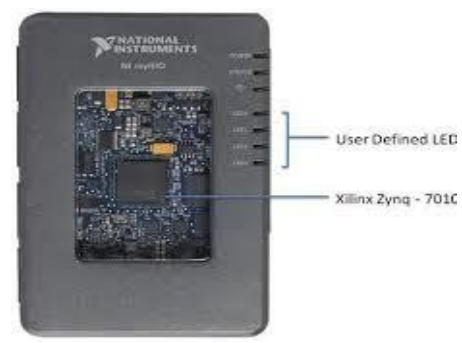

Fig. 2. My Rio

\subsection{Accelerometer}

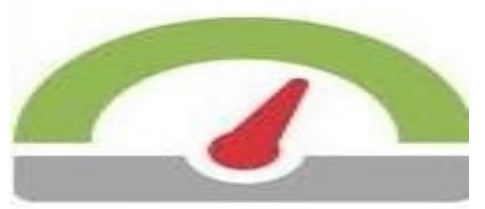

Fig. 3. Accelerometer

To measure the acceleration forces in electro-mechanical components this device is more suitable. According to acceleration forces, this speed is also displayed. These forces accelerometer can detect can be static or dynamic, like the continuous gravity force, and is the case of mobile devices it identified movement or vibrations.

\subsection{LED}

Here Light Emitting Diodes (LEDs) devices are used to display the binary number. These are used as indicators. In the proposed system, the alcohol sensor will sense the signal and gives it to the comparator. This comparator will compare the identified signal with the threshold level. The comparator gives the binary number as input to the My RIO. My RIO with the 5-power supply to these LEDs.

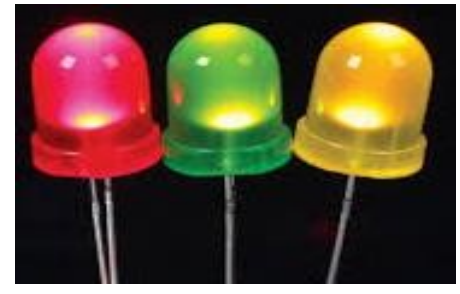

Fig. 4. LED lights

The block diagram of the project is shown in fig.5. 


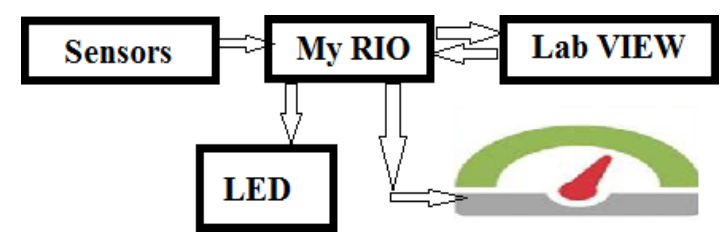

Fig. 5. Block Diagram of the Proposed Project

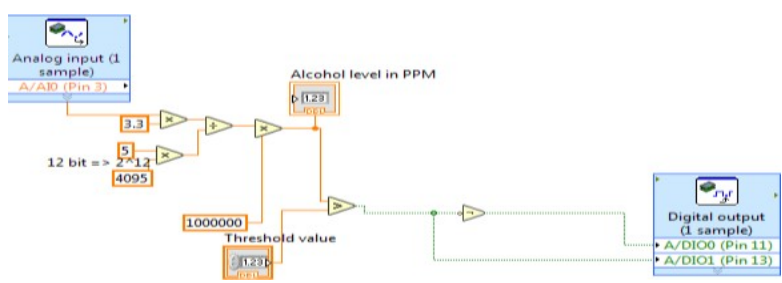

Fig. 6. Lab View Circuit Diagram of the threshold value

After selecting the component just design the fig.6, code by connecting Analog input and Digital output. The threshold value and alcohol level detection value those again connected to the greater symbol if it is less than that threshold value noted there in the circuit diagram than the green led will be glow, if it is more than the threshold value then the red led will be glow and accelerometer gets to zero. After designing the code, we have to run the code in the front panel which is displayed below. In the below figure we can increase the threshold value so that alcohol level can be seen in ppm.

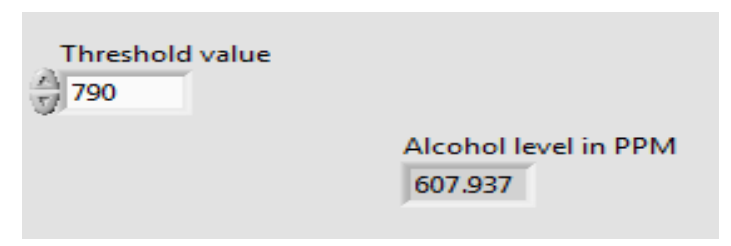

Fig. 7. Front Panel Window

\section{$4 \quad$ Results and Observation}

In Fig.8, The above figure describes the threshold value which is greater than the threshold value then we get RED led light it will be glow if it is less than that number, we will get GREEN led will be glow. From the above diagram \&below diagram, we can observe the indication to led. 


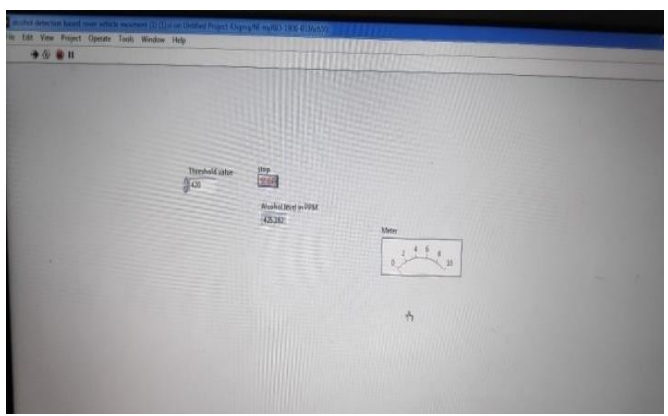

Fig. 8. Front Panel of LabVIEW

Lab VIEW is a tool that is playing a major role here by using graphical programming instead of other microcontrollers. In Fig.9 it indicates the LED RED when the threshold value is greater than the value.

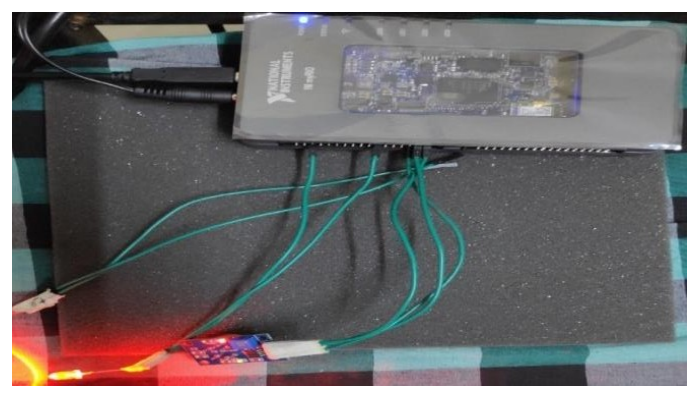

Fig. 9. Indication of Led Red

Here Lab VIEW is replacing Arduino and other microcontrollers that required complex programming. Fig. 10 and 11 are showing the indication of led according to the threshold value readings.

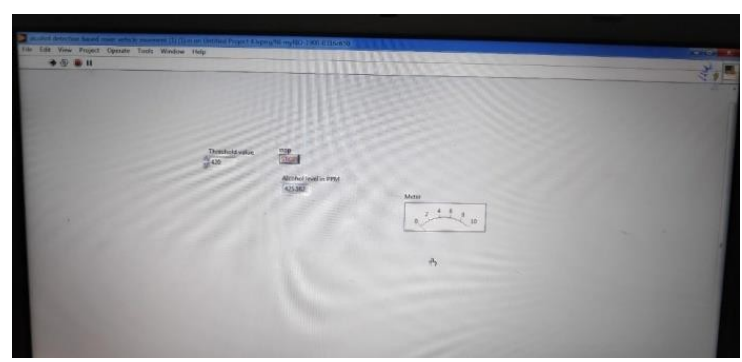

Fig. 10. Front Panel of Window (below threshold reading)

If the alcohol level value is below than threshold value then we get a GREEN LED light which we observe in the below diagram Fig 11. 


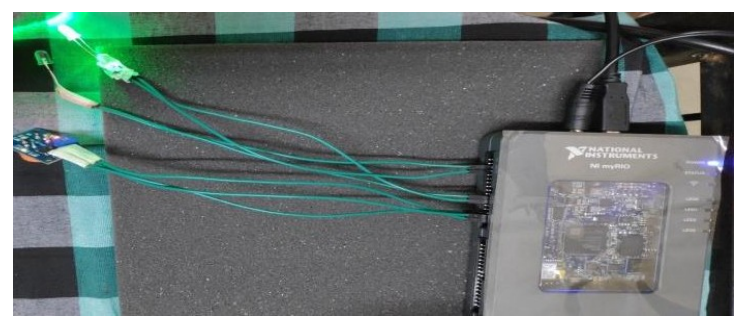

Fig. 11. Indication of LED Green

\section{Conclusion}

In this project, we have proposed and implemented a real-time model that can automatically lock the engine when a drunken driver with a high threshold level tries to drive a car. Due to which Nowadays car accidents are mostly seen. An alcohol sensor is a device placed in the car, using which we can safeguard the life of the person. It has low maintenance costs and low power consumption. Based on the results got in this research, the following conclusions can be obtained. Due to the consumption of alcohol and the influence of alcohol, most drivers tend to be more adventurous in their abilities of judgment, vigilance, recognition, reaction, and braking acts. This is a developed design to efficiently and effectively work for drunk and drivers. Implementation of this design gives a safe car journey which is possible to decrease the accident rate due to drinking. In this design accidents due to drunken drivers will reduce. While using new technology MY RIO we can reduce the complexity of the design. By this, we concluded that when the green LED glows, that indicates that the driver is in a control state. If red LED glows, that indicates that the driver crosses the limit and hence, the accelerator turns to zero and the vehicle will automatically.

\section{Acknowledgement}

This work is supported by grant no.SR/FST/college 017/2017 under DST FIST program-2017, received by Department of Electronics \& Communication Engineering, CMR Technical Campus, Hyderabad.

\section{$7 \quad$ References}

[1] D. Kael, W. J. Firth, and T. L. Patterson, (2004). The influence of alcohol, age, and the number of passengers on the night-time risk of driver fatal injury in New Zealand. Accident Analysis and Prevention, vol. 36, no. 1, pp. 49-61, 2004. https://doi.org/10.1016/s00014575(02)00114-8

[2] European Commission. (2003): Saving 20000 lives on our roads. Technical Report COM 2003/311, European Road Safety Action Program, Luxembourg, 2003. 
[3] NHTSA, (2010) Assessing the feasibility of vehicle-based sensors to detect alcohol impairment, Technical Report, DOT HS, 811 358, National Highway Traffic Safety Administration, US Department of Transportation, Washington, DC, USA, 2010.

[4] Y. Li, D. Die, G. Nia, and J. Zhang (2012) The drink driving situation in China, Traffic Injury Prevention, vol. 13, no. 2, pp. 101-108, 2012.

[5] A. Arendt, W. Wilde, M. Munt, and M. Maclean (2000) Simulated driving performance following prolonged wakefulness and alcohol consumption: separate and combined contributions to impairment, Journal of Sleep Research, vol. 9, no. 3, pp. 233-241, 2000. https:// doi.org/10.1046/j.1365-2869.2000.00216.x

[6] Y.C. Liu and C.H. Ho (2010) Effects of different blood alcohol concentrations and postalcohol impairment on driving behavior and task performance, Traffic Injury Prevention, vol. 11, no. 4, pp. 334- 341, 2010. https://doi.org/10.1080/15389581003747522

[7] E. Chamberlain and R. Solomon (2002) The case for a $0.05 \%$ criminal law blood alcohol concentration limit for driving, Injury Prevention, vol. 8, supplement 3, pp. iiil-iii17, 2002. https://doi.org/10.1136/ip.8.suppl 3.iii1

[8] H. Nash, Alcohol and Caffeine (1962): A Study of Their Physiological Effects, Charles C. Thomas, Springfield, Ill, USA, 1962.

[9] NHTSA (2008) A review of the literature on the effects of low doses of alcohol on drivingrelated skills, Tech. Rep. HS-809 028, National Highway Traffic Safety Administration, Washington, DC, USA, 2008.

[10] A. J. Adams, B. Brown, G. Haegerstrom-Portnoy, M. C. Flam, and R. T. Jones (1978) Marijuana, alcohol, and combined drug effects on the time course of glare recovery, Psychopharmacology, vol. 56, no. 1, pp. 81-86, 1978. https://doi.org/10.1007/bf00571413

[11] NHTSA (1980) Effects of alcohol on driver's visual information processing, Tech. Rep. PB81- 172751, National Highway Traffic Safety Administration, US Department of Transportation, Washington, DC, USA, 1980.

[12] A. M. Williamson, A.-M. Feyer, R. P. Mattick, R. Friswell, and S. Finlay-Brown, (2001) Developing measures of fatigue using an alcohol comparison to validate the effects of fatigue on performance, Accident Analysis, and Prevention, vol. 33, no. 3, pp. 313-326, 2001. https://doi.org/10.1016/s0001-4575(00)00045-2

[13] M. Linnoila, C. W. Erwin, D. Ramm, and W. P. Cleveland (1980) Effects of age and alcohol on psychomotor performance of men, Journal of Studies on Alcohol, vol. 41, no. 5, pp. 488495, 1980. https://doi.org/10.15288/jsa.1980.41.488

[14] J. C. Laberg and T. Loberg (1989) Expectancy and tolerance: a study of acute alcohol intoxication using the balanced placebo design, Journal of Studies on Alcohol, vol. 50, no. 5, pp. 448-455, 1989. https://doi.org/10.15288/jsa.1989.50.448

[15] A. M. Smiley (1986) Marijuana: On-road and driving simulator studies, Alcohol Drugs Driving, vol. 2, no. 3-4, pp. 121-134, 1986

[16] E. L. R. Harrison and M. T. Fillmore (2005) Are bad drivers more impaired by alcohol? Sober driving precision predicts impairment from alcohol in a simulated driving task, Accident Analysis, and Prevention, vol. 37, no. 5, pp. 882-889, 2005. https://doi.org/10.1016/ j.aap.2005.04.005

[17] E. L. R. Harrison, C. A. Marczinski, and M. T. Fillmore (2007) Driver training conditions affect sensitivity to the impairing effects of alcohol on a simulated driving test, Experimental and Clinical Psychopharmacology, vol. 15, no. 6, pp. 588-598, 2007. https://doi.org/10. 1037/1064-1297.16.2.177

[18] M. T. Fillmore, J. S. Blackburn, and E. L. R Harrison (2008) Acute disinheriting effects of alcohol as a factor in risky driving behavior," Drug and Alcohol Dependence, vol. 95, no. 12, pp. 97-106, 2008. https://doi.org/10.1016/j.drugalcdep.2007.12.018 


\section{Authors}

Dr. K. Bharath Kumar, is working as Associate Professor in Dept. of ECE, CMR Technical Campus, Kandlakoya. Hyderabad,501401. He completed his Ph.D. on millimeter wave components in 2019.

Dr. Ch. Sudhamani is working as Associate Professor in Dept. of ECE, CMR Technical Campus, Kandlakoya. Hyderabad, 501401. She completed her Ph.D. on Cognitive Radio in 2019.

Mohd. Abdul Naqi isworking as Assistant Professor in Dept. of ECE, CMR Technical Campus, Kandlakoya. Hyderabad, 501401. He is doing research on the LabVIEW program for IoT applications.

S. Mallesh Narayana is working as Assistant Professor in Dept. of ECE, CMR Technical Campus, Kandlakoya. Hyderabad, 501401. He is doing research on the LabVIEW program for IoT applications.

Article submitted 2020-09-15. Resubmitted 2020-10-24. Final acceptance 2020-10-26. Final version published as submitted by the authors. 